\title{
Etiology and management of esophageal impaction in children: A review of 11 years
}

\author{
Baraa Alabd Alrazzak, Awni Al-Subu, Yoram Elitsur
}

Department of Pediatrics, Section of Gastroenterology, Marshall University, Joan C. Edwards School of Medicine, Huntington, West Virginia, USA

\begin{tabular}{|c|}
\hline Access this article online \\
\hline Website: www.avicennajmed.com \\
\hline DOI: 10.4103/2231-0770.114113 \\
\hline Quick Response Code: \\
\hline
\end{tabular}

\section{ABSTRACT}

INTRODUCTION: Esophageal impaction in children is a medical emergency that needs an immediate medical attention. In the last years multiple objects have been detected and were removed endoscopically. In the last decade, Eosinophilic Esophagitis (EoE) has been associated with esophageal stenosis, leading to esophageal impaction with various objects including toys, food, coins and other. AIM: To determine the various objects and symptoms associated with impactions and to develop algorithm that guides Emergency Department Physicians and Primary care Providers when facing such problem in pediatric patient. MATERIAL AND METHODS: A retrospective chart review of all children referred to the pediatric gastroenterology service at Marshall University for FB impaction between 2000 and 2010 was performed. Foreign bodies treated by other specialties were excluded from this review. Clinical and demographic data were retrieved. RESULTS: A total of 291 charts with the diagnosis of foreign body reviewed of which only 126 met the inclusion criteria and considered for final calculation. Male/Female ratio and mean age were $1.17: 1.0$, and $3.65 \pm 0.75$ years, respectively. Time of impaction before ER evaluation was: $<24 \mathrm{hrs}$ in 75 patients, $>24 \mathrm{hrs}$ in 17 and in 34 the time of ingestion was not known. Radiology was performed in 118 patients, of whom 1 had pneumo-mediastinum and 1 had pneumothorax. Endoscopic localization of the objects showed: 81- proximal, 23middle esophagus, and 22- in the distal esophagus. The esophageal mucosa showed nonspecific changes in 37 patients, 5 with EoE features, 1 patient with hiatal hernia, 1 patient with candidiasis, and in 5 pts had no mucosal description. CONCLUSION: Children with foreign body in the esophagus are commonly seen in our Hospital ER. Those children may harbor undiagnosed medical conditions that will need future therapy. Careful endoscopic assessment with mucosal biopsies is needed to diagnose those conditions earlier. Referral to a GI specialist may be warranted.

Key words: Foreign body, impcation, eosinophilic esophagitis

\section{INTRODUCTION}

Foreign body (FB) impaction in children is a common medical phenomenon, mainly seen in children younger than 3 years of age. ${ }^{[1]}$ The American Association of Poison Control reported more than 93,000 case of FB ingestion in 2009. ${ }^{[2]}$ Most FBs pass through the digestive tract naturally, while a small percentage stacks and becomes a medical problem that might require immediate interventions. ${ }^{[3]}$ GI impaction is usually referred to the pediatric gastroenterology services; but since this specialty is not available in many places, other services, i.e., Ear, Nose \$ Throat (ENT) or surgery might be involved.
In the current study, we present our experience in children who ingested foreign bodies and were referred to our gastroenterologic service at Marshall University School of Medicine in Huntington, West Virginia. We reviewed our practice in the last 11 years and suggest a clinical algorithm for the Emergency Department (ED) physicians and other providers who may encounter with this medical problem.

\section{MATERIALS AND METHODS}

A retrospective chart review of all children referred to the pediatric gastroenterology service at Marshall University for FB impaction between 2000 and 2010 was performed.

Address for correspondence: Dr. Baraa Alabd Alrazzak, Department of Pediatrics, Section of Gastroenterology, Marshall University, Joan C. Edwards School of Medicine, Huntington, West Virginia, USA. E-mail: bara.razak@gmail.com 
Foreign bodies treated by other specialties were excluded from this review. Clinical and demographic data were retrieved. For children who proceeded with a follow-up appointment in the gastroenterology clinic, the clinical data were also reviewed.

\section{Table I: Presenting symptoms (\# I 26 points)}

\begin{tabular}{lc}
\hline Nausea and vomiting & (\%) \\
Dysphagia & $38(30)$ \\
Chocking & $23(18)$ \\
Cough & $16(12)$ \\
Drooling & $14(10)$ \\
Wheezing and stridor & $12(9)$ \\
Odynophagia & $11(9)$ \\
Asymptomatic & $10(8)$ \\
Fever & $9(7)$ \\
Chest pain & $7(5)$ \\
Hematemesis & $6(4)$ \\
Shortness of breath & $3(2)$ \\
Perioral cyanosis & $2(1)$ \\
Abdominal pain & $1(<1)$ \\
\hline
\end{tabular}

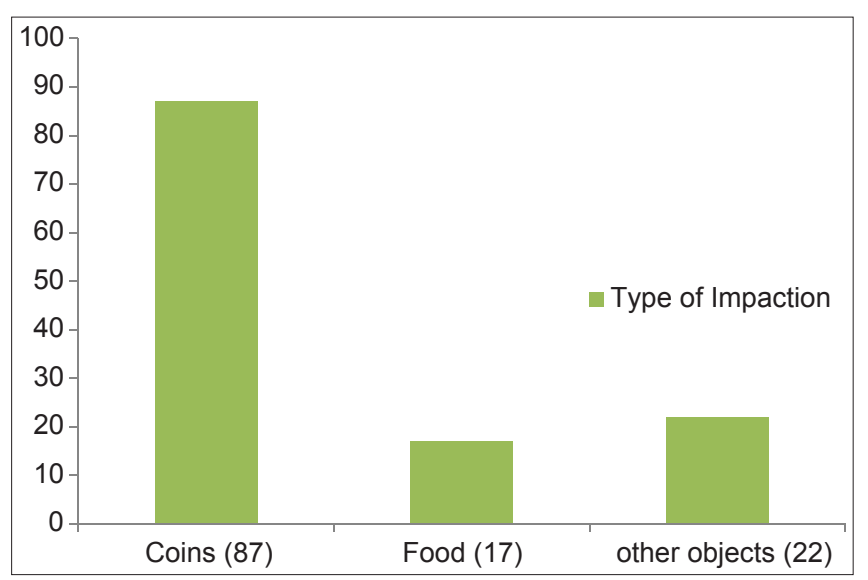

Figure 1a: Type of impaction

\section{RESULTS}

During the study period, a total of 291 children (aged 1-18 years) were diagnosed with FB ingestion local in the GI tract, of whom 126 had the FBs were in the esophagus and this group constituted our study population. The male/female ratio and the mean age were 1.17:1.0, and $3.65+0.75$ years, respectively. The time of ingestion before the ER evaluation was less $24 \mathrm{~h}$ in 75 patients (60\%), longer than $24 \mathrm{~h}$ in 17 patients (13\%), and was unknown or not recorded in 34 patients (27\%). Radiologic documentation was performed in 118 patients (93\%). The anatomical distribution of impaction was described in the proximal esophagus in $81(65 \%)$ children, mid esophagus in $22(17 \%)$, and the lower esophagus in $23(18 \%)$. The presenting symptoms are described in Table 1. Type of FB impaction is illustrated in Figure 1a and b. A suggested algorithm for therapy for the different types of FBs (coins and batteries) is presented in Figure $2 a$ and $b$. The diagnosis of eosinophilic esophagitis (EoE) was made in five patients of those two swallowed coins (age: 28 and 36 months), esophagoastroduodenoscopy demonstrated furrows in the mucosa with no esophageal stenosis and biopsies were positive for large numbers of eosinophils (more than 20 in high power field (HPF)) [Figure 3].

\section{DISCUSSION}

FB ingestion is a common medical problem in young children; most ingested objects pass through the gastrointestinal system naturally and require no intervention. In general, the management approach of FB impaction depends on: The type of object, anatomic location and the presenting symptoms. The present study showed

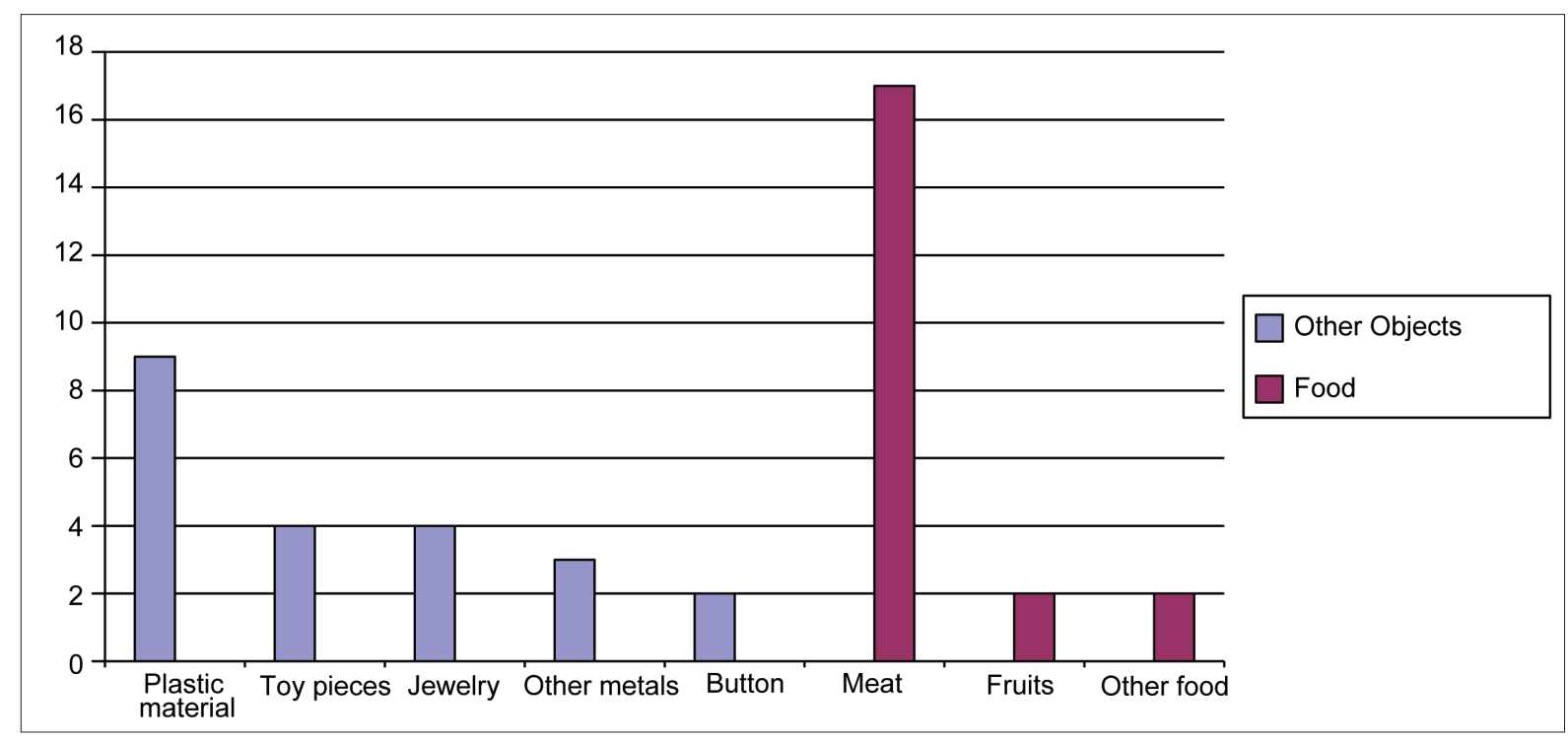

Figure 1b: Type of impaction 


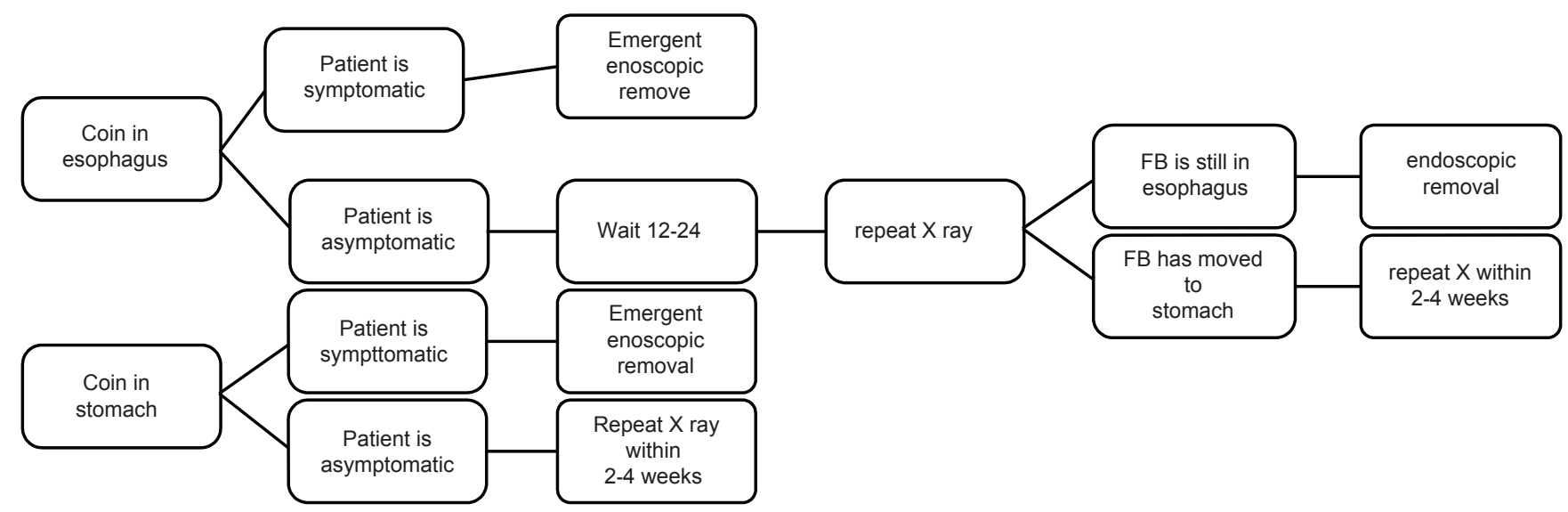

Figure 2a: Coins management ${ }^{[1]}$

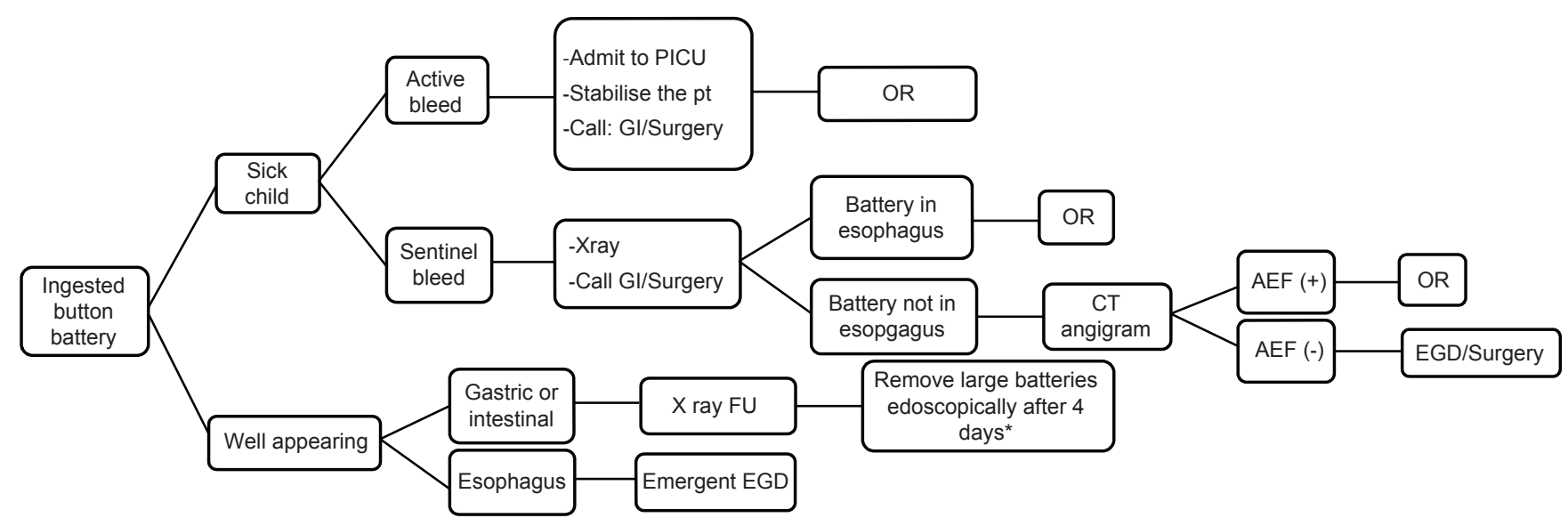

Figure 2b: Battery management. ${ }^{[10]}{ }^{*}$ ASGE guidelines recommended removal after $48 \mathrm{~h}$ if the battery is $>20 \mathrm{~mm}$ in diameter ${ }^{[12]}$

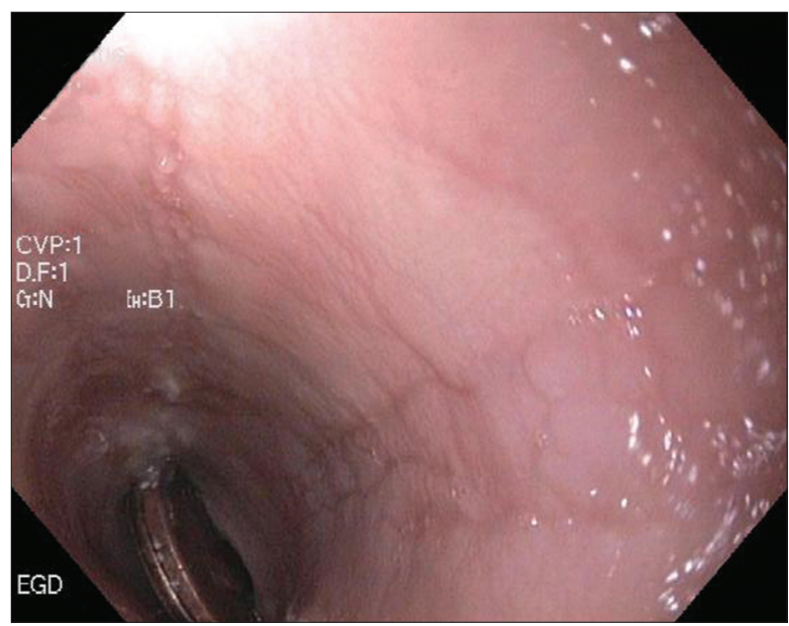

Figure 3: Furrows eosinophilic esophagitis and two coins in the distal esophagus

that most common cause of esophageal impaction were coins, other objects include but not limited to: Toy pieces, round objects (watch batteries, balls, and rings), sharp objects (nails, screws). ${ }^{[4]}$

FBs that bypass the esophagus to the stomach usually caused no symptoms and no endoscopic intervention is needed in most cases. A follow-up a weekly/bi-weekly follow-up X-ray and stool examination to verify exit would be sufficient [Figure 2a and b]. Sharp objects are more likely to cause complication and/or be associated with higher morbidity. ${ }^{[5]}$ The common approach to sharp objects is related to the size of the object and the anatomic location. Sharp objects in the stomach or beyond should be followed by daily radiograph, and if no progress noted in 3 days, surgical consultation may be warranted. ${ }^{[6]}$ On the other hand, any sharp object in the esophagus should be removed within $24 \mathrm{~h}$ regard less of patient's symptoms. Objects longer than $6 \mathrm{~cm}$ and/or wider than $2 \mathrm{~cm}$ are less likely to pass and endoscopic removal should be considered to avoid complications. ${ }^{[7]}$

In summary, all esophageal FBs (coins, batteries, and sharp objects) require an immediate attention and endoscopic retrieval is needed within 0-24 h depending on the type of the FB and the clinical presentation [Figure $2 \mathrm{a}$ and $\mathrm{b}]^{[1,8,9]}$

Previous reports showed that esophageal FBs may be found several days after ingestion if the accident was not witnessed and the child was asymptomatic. ${ }^{[7]}$ In our study, $60 \%$ of the patients arrived at the local ER within $24 \mathrm{~h}$ of ingestion, and 


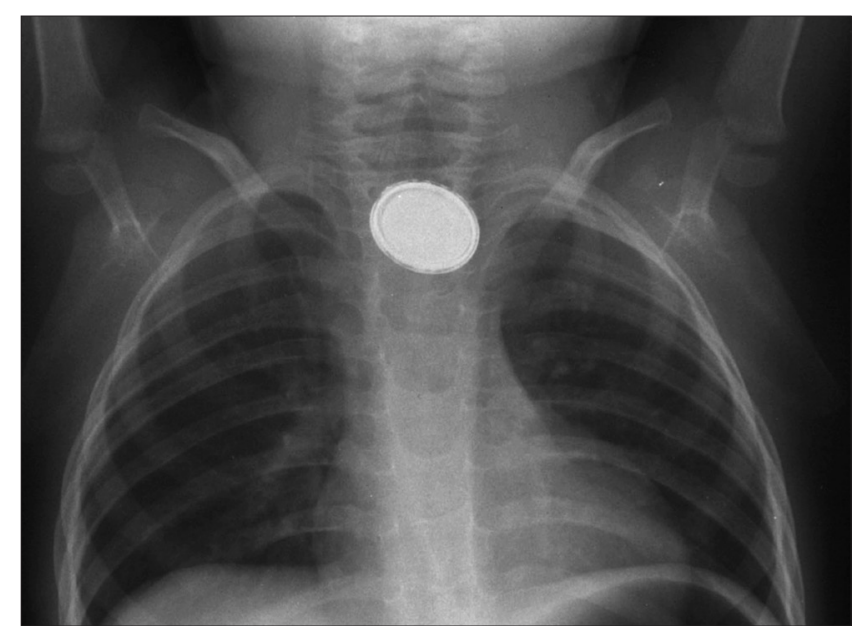

Figure 4: Battery in the proximal esophagus

$17 \%$ after more than $24 \mathrm{~h}$ (up to 6 weeks); $7 \%$ of patients were asymptomatic at the time of evaluation. Radiological studies were ordered in most of the patients (93\%) to confirm the location [Figure 4]. Current recommendations suggest an early referral to the ER and $\mathrm{X}$ ray evaluation in all patients with suspected FB ingestion even if asymptomatic. ${ }^{[1-10]}$

In the last decade, a new diagnosis of Eosinophilic Esophagitis (EoE) was established; clinical and pathological characteristics of the disease have been studied and described. ${ }^{[1]}$ Esophageal food impaction is a well-known presenting symptom in those patients. ${ }^{[9-11]}$ In this review, 5 patients presented with esophageal impaction and diagnosed with EoE, of those, three presented with food impaction and two with coins. In all cases, the endoscopy revealed classic endoscopic features of EoE [Figure 3], and the biopsies confirmed the diagnosis later. Those children followed in the gastroenterology clinic and received proper therapy (Proton pump inhibitor and/or topical steroids). It is recommended that esophageal biopsies should be performed in all patients with food or FB impactions in order to allow for diagnosis and management of the underlying disease, i.e., EoE. ${ }^{[12]}$

In summary, the present study reports our experience with children who referred or presented with esophageal impaction. Although most of the FBs will pass naturally, some cases require urgent assessment and evaluation by the specialist for emergent removal. The limited number of pediatric gastrointestinal specialists may expose the children to a higher risk for morbidity and possible mortality. Consequently, we suggest a clinical algorithm to assist the pediatricians and ER physicians in managing those children and referred them to the specialized centers at the proper time if needed.

\section{REFERENCES}

1. Webb WA. Management of foreign bodies of the upper gastrointestinal tract. Gastroenterology 1988;94:204-16.

2. Top substance in pediatric exposures (age 0-5). American Association of Poison Control. Available from: https://aapcc.s3.amazonaws.com/pdfs/ annual_reports/NPDS_Annual_Report_2009_1.pdf . [Last accessed on 2013 Feb 1].

3. Kay M, Wyllie R. Pediatric foreign bodies and their management. Curr Gastroenterol Rep 2005;7:212-8.

4. Arana A, Hauser B, Hachimi-Idrissi S, Vandenplas Y. Management of ingested foreign bodies in childhood and review of the literature. Eur J Pediatr 2001;160:468-72.

5. Kay M, Wyllie R. Techniques off oreign body removal in infants and children. Tech Gastrointest Endos 2002;4:188-95.

6. Eisen GM, Baron TH, Dominitz JA, Faigel DO, Goldstein JL, Johanson JF, et al. Guideline for the management of ingested foreign bodies. Gastrointest Endosc 2002;55:802-6.

7. Ikenberry SO, Jue TL, Anderson MA, Appalaneni V, Banerjee S; ASGE Standards of Practice Committee. Management of ingested foreign bodies and food impactions. Gastrointest Endosc 2011;73:1085-91.

8. Liacouras CA, Furuta GT, Hirano I, Atkins D, Attwood SE, Bonis PA, et al. Eosinophilic esophagitis: Updated consensus recommendations for children and adults. J Allergy Clin Immunol 2011;128:3-20.e6.

9. Hurtado CW, Furuta GT, Kramer RE. Etiology of esophageal food impactions in children. J Pediatr Gastroenterol Nutr 2011;52:43-6.

10. Jackson RM, Hawkins DB. Coins in the esophagus. What is the best management? Int J Pediatr Otorhinolaryngol 1986;12:127-35.

11. Uyemura MC. Foreign body ingestion in children. Am Fam Physician 2005;72:287-91.

12. Brumbaugh DE, Colson SB, Sandoval JA, Karrer FM, Bealer JF, Litovitz T, et al. Management of button battery-induced hemorrhage in children. J Pediatr Gastroenterol Nutr 2011;52:585-9

Cite this article as: Alrazzak BA, Al-Subu A, Elitsur Y. Etiology and management of esophageal impaction in children: A review of 11 years. Avicenna J Med 2013;3:33-6.

Source of Support: Nil, Conflict of Interest: None declared. 